According to Hogg, the costs of overhead and communications in family health teams may have been underestimated. But even if team-based care turns out to be more expensive, says Hogg, the improvement in quality of care makes the investment worthwhile.

"I'd like to see the government stay the course," says Hogg. "One of the worries I have is that this is very expensive, and it takes a long time to get to the point where it pays a dividend. My concern is that if the government focuses on quick returns, it will grow impatient and move on to some other initiative."

A recent study suggests that not only has this initiative paid dividends, it has been so effective that the United States should consider following Ontario's lead (Ann Fam Med 2011;9:165-71). The Ontario model of team-based primary care may be "North America's largest example of a patient-centred medical home," stated the study, which found several advantages to family health teams, including higher rates of patient satisfaction, as well as higher income and job satisfaction among physicians. Medical students also appear to be more likely to pursue family medicine if they can work on teams.

Overall, though, the research on the effectiveness of primary care teams is inconsistent. In 2007, the Canadian Health Services Research Foundation published a synthesis of available data (www.chsrf.ca/Migrated/PDF/Research Reports/CommissionedResearch/Syn thesisReport_E_rev4_FINAL.pdf). It found that although the amount of highquality research in the area was growing, there were still "large quantities of low- and very low-level evidence."

Furthermore, there are many gaps in the literature. For example, there is limited evidence of how varying team structure affects health outcomes. There is little information on the effects of interprofessional collaboration at the provider and system levels, such as how it affects costs. And though studies have shown positive results in some areas of care - such as mental health care and chronic disease prevention and management - there is limited "moderate- to high-quality evidence" that indicates primary care teams produce better health outcomes in general patient populations.

Hogg and Scott Reeves, associate professor at the University of Toronto's faculty of medicine and editor-in-chief of the Journal of Interprofessional Care, say the Ontario government pushed ahead with family health teams despite the paucity of research on interprofessional collaboration in primary care. "It was an activity undertaken more on enthusiasm than evidence," says Reeves.

Reeves is now helping to provide that evidence, having recently con- tributed to a study on family health teams that highlighted the importance of issues such as leadership, roles and scopes of practice - issues of particular concern to family physicians, whose "identity can be perceived as undergoing a considerable transition at this stage of primary care reform (Can Fam Physician 2010;56:e368-74).

"To have good teamwork, you need clear roles and responsibilities. There has to be regular interaction and feedback on performance, says Reeves, who notes that "tension points" can occur when suggestions are made that someone other than a doctor, such as a nurse, lead a health team - a problem "compounded by hundreds of years of physician and nurse interactions based on one of them being dominant in terms of income and status."

Reeves' study also noted that much of the positive feedback on family health teams stems from perceptions, not empirical evidence. "Such perceptions are important, as they can have implications for satisfaction of the team as well as its morale," the paper states. "Such perceptions, however, require further evaluation to understand their relationships to the realities of accessibility of care and improvement in patient health outcomes." - Roger Collier, CMAJ

CMAJ 2011. DOI:10.1503/cmaj.109-3864

\title{
Disparate prescriptions in desperate times
}

I deological rants, wish lists, assertions of values, pleas for the disadvantaged and homages to the tenets of free enterprise. Desperate and disaffected souls expressing frustration over inadequate or inequitable care. Privileged and well-heeled professionals disdaining the "lifestyle choices" of the impoverished and uneducated.

The Canadian Medical Association's town hall meetings on health care transformation have been nothing if not a microcosm of Canadian opinion on the merits and values of their health care system and the sixth and final forum in Ottawa, Ontario, was no exception.

The system was lambasted and lauded. It needs money and has too much money. It lacks coherence and oversight, and is rigid and micromanaged.

As vast as the range of diagnoses were the prescriptions, which were alternately thought-provoking, and less so.

Among those offered at the June 7 forum, structured around the topic "Health Care in Canada: Time to Rebuild Medicare," were:

- Reduce the pressure on expensive emergency departments by obligating family doctors and primary care teams to be open for business from 7 am to 10 pm, Monday through Sunday.

- "Punish" Canadians who do not take personal responsibility for their own health and the demands they place on the health care system by smoking and overeating.

- Axe waste such as unnecessary diagnostic imaging.

- Hold doctors to "standards of care" and abandon the fiction that proper treatment can be achieved through a proverbial "seven-minute visit."

- Provide an obstetrician for every village.

- Establish clear and firm guidelines for "rationing" care.

The opinions advanced at all six town hall gatherings have been nothing if not diverse and "passionate," says CMA President Dr. Jeff Turnbull. 
"People have experienced weaknesses in a failing health care system. They've suffered as a consequence, either with their health, or their family's health. They've come because they want to see meaningful change and they want the health care system to be better for future generations."

"There's a universal sort of sense that they're all talking about issues of inequity. They're all talking about issues of lack of access to meaningful services throughout the continuum and they talk about health social policies and social determinants of health. They talk about the need for health promotion strategies and they talk about longterm care. They often talk about the need to die at home and reasonable palliative care services."

Canadians who attended the town halls also spoke frequently about the inadequacy of a health care system that uses acute care settings to treat chronic diseases, and about the deficiencies a policy-setting process that seems fundamentally incapable of making comprehensive, integrated changes, Turnbull adds. "We have a political decision-making system that has a short vision. We have challenges between the federal, provincial and territorial jurisdictions in care. We have silos in care that make it very difficult to move funds and resources and people between settings. We have lack of a clear consensus and vision amongst decision-makers."

The six town hall meetings, though, have forged a consensus around several points, Turnbull argues.

Those include a sense that health care providers and patients must establish themselves as a political constituency that will essentially "force decision-makers to lead and to have the courage to lead."

As well, there is a consensus that there is a need for far more accountability from both users and providers of health care, Turnbull adds. Physicians "have to use the system much more effectively or manage it. And we have to be better custodians of the health care system. So we have to be people who create and follow practice guidelines. ... We have to hold ourselves accountable for what we do in a trans-

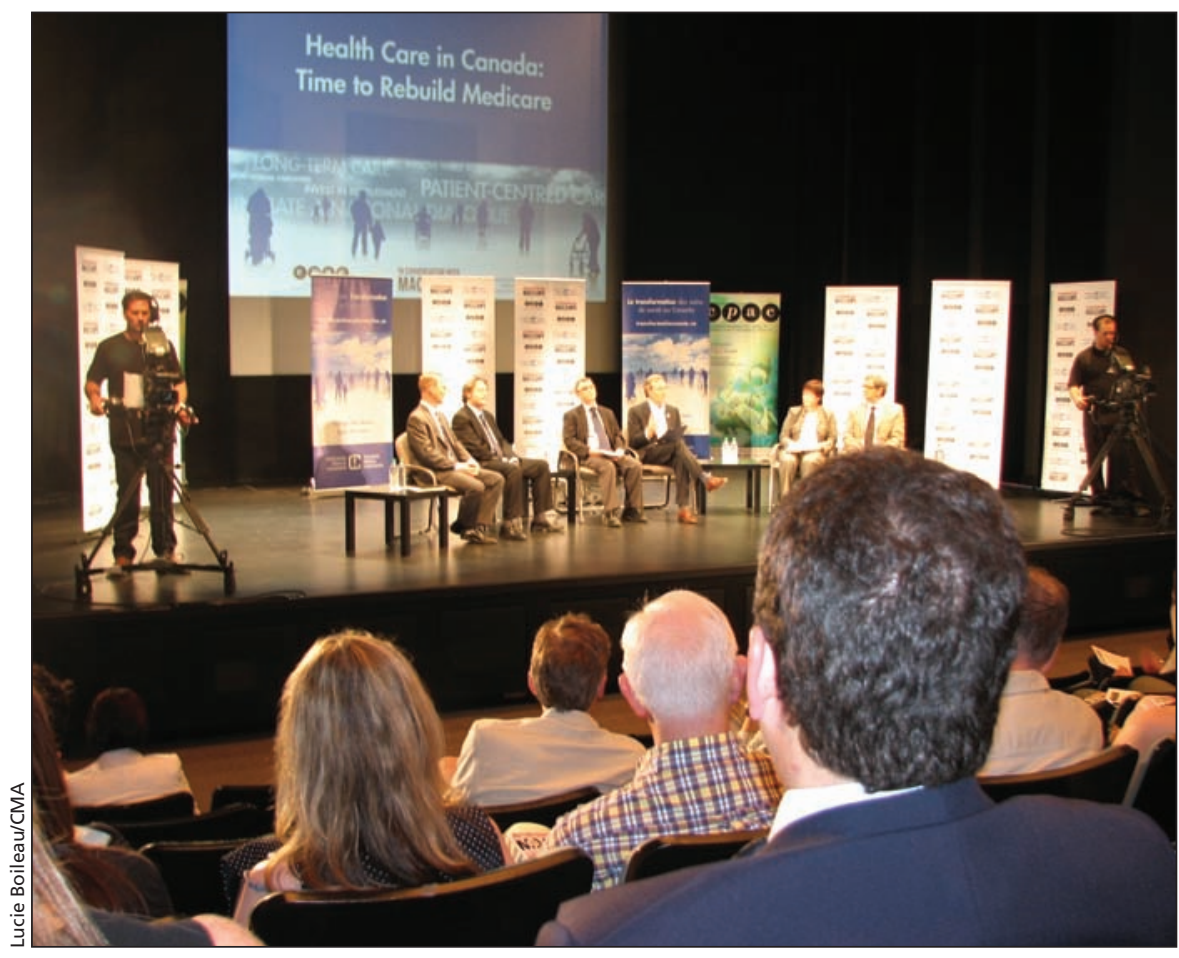

Canadians attending the CMA's town hall meetings on health care transformation offered a vast range of diagnoses about the ailments of the health care system, and as vast a range of prescriptions.

parent fashion. And that we have to be willing to work in consensus and in teams and allow the patient to accept ownership of their problems."

The town hall meetings also provided ample evidence that systemic rather than piecemeal reform of the health care system is required, Turnbull says, citing as an example of the latter, the lengthier wait times that were experienced for clinical procedures that were not targeted priorities in the multibillion dollar federal wait times initiative (which focused on joint replacement, cataract surgery, coronary artery bypass grafts, radiation therapy and diagnostic imaging). Similarly, he says, lengthy wait times in emergency departments are often no more than a function of $100 \%$ occupancy rates resulting from patients waiting for access to long-term care beds.

"Solutions have to be integrated, complex, thoughtful, evidence-based, strategic and done over a period of years," Turnbull says. "This will not be a quick fix. And it won't be done by doctors. It will be done by groups, partnerships, providers and the public."

The six town hall meetings were part of a broader public consultation exercise that the CMA launched in 2010 to spark an "adult conversation" on updating and expanding the Canada Health Act (www.cmaj.ca/cgi/doi /10.1503/cmaj.109-3333).

Turnbull says CMA will distill the opinions expressed by participants and panelists at the town hall meetings, the recommendations of a blue-ribbon advisory panel (whose composition and terms of reference have not been publicly disclosed) and advice offered in more than 700 online submissions at the association's transformation website (www.healthcaretransformation .ca/en/) into a plan featuring "specific action items" regarding the next steps needed to be taken to achieve transformation of the health care system.

"It's too important to allow this to be lost. Those people who think that health care is static are wrong. Health care is changing around us immediately. I don't happen to like the direction it's going. And I think it's incumbent on all of us to say 'no, we don't want to go in that direction'," Turnbull adds. "That sense of apathy, we've got to get over that." - Wayne Kondro, CMAJ

CMAJ 2011. DOI:10.1503/cmaj.109-3918 